Letramento dominante e prática social: reflexões sobre a linguagem jurídica e a relação de poder com o jurisdicionado

Luzia Fernandes do Nascimento

*Mestranda em Linguística pela Universidade Federal do Piauí - UFPI - 2019.1

Resumo: Sabe-se que o objetivo precípuo da língua em qualquer comunidade de fala é comunicar. No âmbito dos espaços jurídicos, seja tribunais, fóruns, sala de audiência ou secretarias forenses, as habilidades de leitura e escrita são de suma importância para que o cidadão participe juridicamente da sociedade de modo abrangente e tenha a tão apregoada garantia de acesso à justiça, consoante dispõe o texto constitucional brasileiro. Dito isso, o presente artigo tem como objetivo refletir sobre, até que ponto, a linguagem jurídica representa um instrumento de poder e segregação entre a justiça e o jurisdicionado, considerando o estilo linguístico presente nas decisões judiciais e a falta de letramento social para atuação do indivíduo nos espaços institucionalizados. Essa reflexão pretendida ancora-se nos postulados dos Novos Estudos de Letramento de Street (1993), Ângela Kleiman (1995) e Tfouni (1995) e, também, embora não seja o objetivo, no conceito de poder simbólico do sociólogo Pierre Bourdieu (1989). Por fim, avoca-se a ideia do uso de uma linguagem jurídica capaz de inserir o jurisdicionado no universo das decisões judiciais, em detrimento do purismo linguístico e, muitas vezes, ininteligível, com fulcro em uma decisão judicial emanada de um juiz do TRF 4, no ano de 2015.

Palavras-chave: letramento, linguagem jurídica, jurisdicionado, poder simbólico

\title{
INTRODUÇÃO
}

Hodiernamente, são grandes os desafios para formar cidadãos proficientes para significar a realidade que os cerca. Não são raras as pesquisas que apontam que, apesar do crescente avanço na universalização do acesso à educação básica, a escola ainda é falha no que diz respeito a instrumentalizar o indivíduo para aspectos básicos sobre leitura e escrita. Em decorrência desse processo falho, tem-se como produto o chamado "analfabeto funcional", denominação dada para brasileiros que possuem limitações para fazer uso da leitura e da escrita e de cálculos matemáticos em situações mais comezinha do cotidiano.

Para tanto, o domínio da leitura e da escrita constituem-se como práticas indissociáveis para atuação no meio social, essenciais para o engajamento do indivíduo como membro de um grupo social disposto a agir, interagir, confrontar e ocupar os espaços de poder possibilitados 
pelos instrumentais da leitura e escrita. Nesse sentido, o não domínio da leitura e escrita acaba por condenar o cidadão a um apartheid social, considerando o valor imprescindível do universo das letras como instrumento de interação em uma sociedade letrada, principalmente no que tange à atuação do cidadão nos espaços jurídicos.

É nesse contexto que surge o letramento como prática necessária para a atuação do indivíduo em uma instituição de extremo prestígio social como é o poder judiciário. No âmbito do Poder judiciário, verifica-se que os espaços jurídicos se assentam sobre práticas de letramentos dominantes, expressão utilizada por alguns estudiosos dos Novos Estudos de Letramento (BAYNHAM,1995; BARTON e HAMILTON 1998, 2000; ROGERS, 2002, apud ) para se referir às práticas de leitura e escrita que estão intrinsicamente relacionadas às posições de poder. Essa expressão carrega uma multissignificação, podendo ser entendida como a prática de letramento para manter e/ou criar relações de dominação, como os usos dominantes do letramento ou até como formas institucionalizadas de utilização de textos e assim por diante.

Em contrapartida, termos outros modelos de letramento, com grau menor de prestigio, vinculados às práticas de leitura e escrita distante dos espaços institucionalizados, como a escola. Nesse aspecto, acaba surgindo práticas de letramento valorizadas e não valorizadas, promovendo um apagamento do indivíduo que não se apropria desse letramento dominante. É nesse sentido que Kleiman (1995), referenciando Street (1993), assevera que as práticas de letramento se constituem aspectos das estruturas de poder em uma sociedade, não se restringindo apenas ao aspecto cultural.

Nessa esteira, Kleiman (1995) afirma que as práticas de letramento mudam segundo o seu contexto. Para tanto, a autora afirma que existem situações em que a escrita "constitui parte essencial para fazer sentido da situação, tanto em relação à interação entre os participantes com em relação aos processos e estratégias comunicativas". Tais situações descritas são denominadas eventos de letramento

Diante disso, considerando que as práticas discursivas mudam de acordo com o seu contexto, têm-se os espaços jurídicos como aqueles em que se sobrepõe o letramento dominante, constituindo-se como entreve no processo de comunicação entre a justiça e o jurisdicionado que a ela demanda. Nesse sentido, a linguagem jurídica, formalizada através de textos diversos, mais especificamente através das decisões emanadas dos julgadores, reveste de instrumento segregador entre o cidadão, portador do letramento não valorizado, e a justiça. 
Nesse viés, o direito e a linguagem jurídica são vistos pelo sociólogo Pierre Bourdieu (1989) como óbice do indivíduo ao sagrado postulado de acesso à justiça e como forma de controle social. O autor considera a linguagem jurídica, tal como se apresenta, como manifestação de poder, em que a comunicação depende de uma relação de poder desigual, à qual o sociólogo dá o nome de poder simbólico. O enfoque dado à Bourdieu à linguagem não se fulcra apenas no processo de comunicação, mas nas relações de autoridade, de valorização ou desvalorização dos diversos discursos que circulam nos mais diversos contextos.

Diante de todo esse arcabouço teórico que ancora esse artigo, vinculando o letramento dominante ao poder simbólico da linguagem jurídica no âmbito do espaço do poder judiciário, este artigo traz a análise de uma decisão prolatada por um membro da justiça, o que é feita no final do artigo. Trata-se de um acórdão cujo relator foi um juiz convocado da 4ạ Turma do Tribunal Regional do Trabalho da 4ạ Região (RS), Dr. João Batista de Matos Danda, redigido em uma linguagem mais simples, com o intuito de aproximar o Judiciário da população.

\section{LETRAMENTO DOMINANTE E PRÁTICA SOCIAL}

Quando se fala em Letramento no Brasil não se pode negligenciar as ideias de Paulo Freire sobre a relação SUJEITO X LINGUAGEM X CONTEXTO SOCIAL, cuja proposta de aquisição da leitura compreende a necessidade de interagir com o social, com a realidade na qual o indivíduo está inserido. Na esteira do pensamento de Paulo Freire (1981), a educação só é libertadora (Pedagogia da Libertação) quando se fundamenta na realidade concreta do educando, ou seja, o ato de acesso à cultura da escrita, por meio da leitura, não pode estar dissociado da cultura, da realidade do indivíduo ou do grupo envolvido.

Sobre o tema, Tfouni (1995) afirma que as perspectivas de letramento se colocam favoravelmente à tese da grande divisa, segundo a qual há uma separação radical entre os usos orais e os usos escritos da língua, sendo estes superiores. Nesse ponto de vista, a estudiosa alinhase ao pensamento de Street (1984) que, numa postura crítica ao grafocentrismo de alguns autores, estabelece uma versão moderna da teoria da grande divisa, em que a relação entre as modalidades oral e escrita da língua aponta para um hibridismo, um imbricamento de formas, de códigos gráfico-visuais, de gêneros discursivos e modelos textuais.

No livro Os significados do Letramento: uma nova perspectiva sobre a prática social da escrita, de Ângela Bastos Kleiman, de 1995, a autora reafirma a complexidade e variação dos tipos 


\section{CONGEESSO CIENCIAESOCIEDADE Inovaç̃o, Diversidaile B Sustentahilitate}

de estudos sobre Letramento e o define como "um conjunto de práticas sociais que usam a escrita, enquanto sistema simbólico e enquanto tecnologia, em contextos específicos, para objetivos específicos".

Nessa obra, Kleiman valida o pensamento de Tfouni (1995) quando afirma que um indivíduo pode ser letrado sem, contudo, saber ler e escrever. Nesses termos, cita vários espaços em que esse processo de letramento acontece, denominados de agências de Letramento, elegendo o espaço escolar como o mais importante, porém restrito à aquisição do código escrito, concebido em termos de competência individual, ao passo que a família, a igreja, a rua, o local de trabalho constituem-se como agências de letramento como prática social.

Quanto às práticas de uso da escrita, a autora retoma as concepções de Letramento denominado modelo autônomo e modelo ideológico de Street (1984), traçando um paralelo entre as duas concepções. O modelo autônomo está centrado na competência individual, numa relação entre a aquisição da escrita e o desenvolvimento cognitivo. É no âmbito desse modelo que se assenta a teoria da grande divisa, já citada, denominada por Ângela Kleiman como a dicotomização entre a oralidade e a escrita. O modelo ideológico é definido pela autora na mesma esteira de Street, em que as práticas de aquisição da escrita, ou práticas letradas são determinadas pelo contexto social.

Kleiman (1995) estabelece o conceito de eventos de letramento com fulcro em um estudo etnográfico de comunidades do sul dos Estados Unidos de Heath (1982, apud KLEIMAN, 1995), como situações em que a escrita é parte essencial numa relação de interação e de processos interpretativos.

Partindo do pensamento de Street (1984), Tfouni (1988) assevera que não existe, nas sociedades modernas, o letramento "grau zero", que equivaleria ao "iletramento", ou ao analfabetismo. Na visão da autora, o que existem são graus de letramento, em decorrência das diferentes práticas discursivas de grupos socioeconômicos distintos.

Todos esses autores concebem Letramento como o uso da leitura e da escritura em práticas sociais, em que os sujeitos, embora não saibam ler nem escrever, sejam analfabetos, mas podem ser, de certa forma, letrados, uma vez que utilizam a leitura e a escrita em práticas sociais de interação. Esse pensamento estabelece uma relação intrínseca entre letramento e práticas sociais, caracterizando-o como o conjunto de habilidades necessárias para que o indivíduo se sobressaia em seu contexto social, o chamado Letramento funcional. 
Em 2002, Magda Soares publica o artigo intitulado Novas práticas de leitura e escrita: Letramento e cibercultura na revista Educação \& Sociedade. Como é recorrente nas obras que tratam desse campo de conhecimento, desde meados dos anos 1980, a autora trata da inexatidão conceitual do termo, o que a leva a afirmar que se trata de um fenômeno de conceitos plurais, no entanto, reafirma a sua visão sobre Letramento, colocando-o em oposição a analfabetismo.

Segundo Soares (2002), existe uma relação estreita entre Letramento e tecnologias digitais de leitura e escrita. Diante disso, levanta reflexões em torno dos impactos da tecnologia da escrita digital sobre os espaços de letramento. Essas tecnologias, segundo a autora, resultam em vários efeitos sociais, cognitivos e discursivos. Diante desse cenário tecnológico ocupado pela leitura e pela escrita, presencia-se o surgimento de várias modalidades diferentes de Letramento. Desta feita, a estudiosa sugere que se pluralize o termo letramento, considerando que não existe Letramento, mas letramentos.

A realidade cultural que está sendo desenhada, ou que já domina os espaços sociais, a partir do uso da rede de computadores e de outros suportes tecnológicos, também se faz presente nas escolas. Sendo o letramento a condição dada ao indivíduo para interagir em seu cotidiano, o termo ganha uma nova perspectiva em face dessas demandas que emergem no âmbito das práticas sociais, fazendo surgir o hipertexto.

\section{O PODER SIMBÓLICO DE PIERRE BOURDIEU}

A linguagem no universo jurídico está inserida no letramento dominante, muito distante de outros tipos de letramentos não canônicos e marginalizados, o que acaba por afastar o cidadão do espaço jurídico, numa afronta ao princípio constitucional de acesso à justiça. A prática do letramento dominante, no seio dos espaços jurídicos, limita-se aos profissionais que postulam em nome de outrem o direito que este acredita ter. No entanto, até mesmo para esses profissionais que militam na seara jurídica, não são raras as vezes em que o purismo linguístico vai de encontro ao objetivo maior da linguagem, qual seja, incluir e não segregar.

Nesse sentido, o direito e a linguagem jurídica se revestem de manifestação de poder, limitador da inserção do indivíduo nos espaços de prestígio social, logo, as relações de comunicação são relações de poder fundadas em um arbítrio, em relações de violência simbólica, socialmente instituídas, conforme estabelece Bourdieu (2002). Neste ponto, o poder simbólico da 
linguagem pressupõe que os dominados se submetem espontaneamente ao controle socialmente construído.

Dessa forma, é notório o fosso que existe entre as normas jurídicas, as decisões judiciais, elaboradas a luz do letramento dominante, e o demandante na esfera judicial, uma vez que todo esse arcabouço linguístico jurídico é criado para tornar inacessível o seu discernimento na correlação com o jurisdicionado.

Nas palavras de Bourdieu, o poder simbólico é consequência dos instrumentos de comunicação e conhecimento, tendo como característica a invisibilidade, uma vez que não é percebido pelos agentes que dele são vítimas. É essa característica da invisibilidade que leva o jurisdicionado à subserviência, levando-o a significar o mundo jurídico natural e racional, residindo aí o poder da linguagem dominante.

É nesses termos que, alicerçado no poder simbólico entre jurisdicionado e a justiça, Bourdieu (1989) afirma que a legitimidade da palavra não é advém da linguagem por si só, mas tem sua origem nas relações sociais que a sustentam e a produzem. Desta feita, são essas relações de poder que produzem e que desconhecem palavras, com o fito de manutenção dessas relações assimétricas, conforme se pode verificar, in verbis:

O poder simbólico como poder de constituir o dado pela enunciação, de fazer ver e fazer crer, de confirmar ou de transformar (...) O que faz o poder das palavras e das palavras de ordem, poder de manter a ordem ou de a subverter, é a crença na legitimidade das palavras e daquele que as pronuncia, crença cuja produção não é da competência das palavras (BOURDIEU, 1989, p. 14 e 15).

Infere-se, portanto, que a linguagem jurídica, com seus excessos, é construído por meio do poder simbólico, que se interpõe entre o jurisdicionado e a justiça, cujo objetivo precípuo, na visão de Bourdieu, é manter a distância e uma suposta independência entre o que ocorre no mundo social e o que é discutido no campo jurídico.

\section{ANÁLISE DE UM ACÓRDÃO REDIGIDO EM LINGUAGEM COLOQUIAL}

Diante de todos os aspectos que permeiam o aceso dos jurisdicionado ao poder judiciário, especialmente no que tange à produção de uma linguagem com fulcro no letramento dominante, construído pelo poder simbólico, urge que profundas reflexões sejam feitas, objetivando a mudança desse quadro. É notório que o processo de comunicação, no espaço jurídico, assenta-se 
não na interação entre os agentes linguísticos, mas na construção de fronteiras de sentido exercidas por poderes simbólicos, socialmente instituídos ou imaginados, como já ressaltado.

Desta feita, urge uma mudança de mentalidade do Estado, através do Poder Judiciário, para reverter essa relação de distanciamento entre o cidadão que demanda a prestação jurisdicional e o Estado Democrático de Direito. Essa mudança perpassa, obrigatoriamente, por um novo modelo do ato comunicativo.

É nesse sentido que se tem verificado um movimento de mudança de paradigma no que tange à tentativa de aproximação entre o cidadão demandante e o poder judiciário como demandado. Traz-se à baila, a título de exemplo desse novo paradigma, a decisão de um juiz trabalhista, em sede de acórdão, convocado da 4a Turma do Tribunal Regional do Trabalho da 4a Região (RS), João Batista de Matos Danda. A decisão foi redigida pelo magistrado, relator do processo, em linguagem mais simples, para, segundo ele, aproximar o Judiciário da população.

A decisão emanada do magistrado teve grande repercussão dentro e fora do mundo jurídico, com ampla divulgação em blogs e sítios especializados, ou não, dada a linguagem inusitada utilizada pelo julgador no que se refere a textos dessa natureza. Criticado por uns, elogiados por outros, o fato é que o juiz conseguiu abrir a discussão sobre a possibilidade do uso de uma linguagem capaz de inserir o jurisdicionado no contexto das decisões judiciais.

Para uma melhor análise, segue abaixo alguns trechos da decisão que merecem destaque. Antes, porém, faz-se necessário descrever o contexto em que se deu a decisão. Tratava-se do Processo Trabalhista no 0000869-29.2013.5.04.0241, em trâmite no estado do Rio Grande do Sul, em que um pedreiro pleiteava o reconhecimento de vínculo de emprego e indenização por danos morais após sofrer acidente em uma obra particular, de propriedade de outrem. A sentença prolatada em sede de 1 o grau considerou improcedentes os pedidos formulados pelo pedreiro. Desta feita, em sede de recurso, o acórdão não reconheceu o vínculo empregatício, mas entendeu que o pedreiro teria direito a receber uma indenização e uma renda mensal a ser paga pelo dono da obra.

Seguem alguns trechos da decisão que merecem destaques. Cumpre esclarecer, a priori, que os nomes das partes foram omitidos, embora tenham sido amplamente divulgados em sítios oficiais da justiça e blogs e se tratar de decisão exposta no Diário oficial, optou-se por tratar as partes como sujeito 1 (Pedreiro) e sujeito 2 (dono da obra). Vejamos alguns trechos da decisão: 
O Juiz do Trabalho de Alvorada entendeu que o Sujeito 1 tinha prestado trabalho por conta própria, em regime de empreitada, e que não foi empregado do Sujeito 2. Negou todos os direitos que reclamava. O pedreiro não se conforma e recorre. E o reclamado, sujeito 2 , com direito a se defender, diz que a sentença do Juiz está certa e quer que seja confirmada. O processo veio de Alvorada para Porto Alegre e me toca dizer quem está com a razão, depois de olhar novamente todas as provas.

(...)

O Juiz de Alvorada ouviu os dois numa audiência e mais três testemunhas. Tem no processo fotos, documentos e perícia também. Depois de examinar tudo, deu razão ao dono da obra. (...)

Para julgar de novo, vou ler as declarações de todos mais uma vez e olhar os documentos. Pode ser que me convença do contrário. Mas pode ser que não. Vamos ver (grifo nosso).

Como visto, o jargão próprio do meio jurídico foi afastado, com a predominância clara de uma linguagem corriqueira e, pode dizer, até mesmo descuidada, conforme se observa no emprego do verbo ter com sentido de existir ou haver, que, embora seja considerado inadequado em linguagem formal, o seu uso numa linguagem coloquial está consagrado em contextos sociais outros. Trata-se do letramento vernacular em detrimento do letramento dominante, numa clara intenção de privilegiar a interação direta entre as partes do processo e o Estado que julga.

O próprio juiz em entrevista ao sítio g1.globo asseverou que o trecho "para julgar de novo, vou ler as declarações de todos mais uma vez e olhar os documentos. Pode ser que me convença do contrário. Mas pode ser que não. Vamos ver", normalmente seria escrito dessa forma: "Inconformado com a sentença, que julgou improcedente a ação, recorre o reclamante buscando sua reforma quanto ao vínculo de emprego e indenização por acidente de trabalho. Com contrarrazões sobem os autos a este tribunal. É o relatório. Passo a decidir".

Verificou-se, ainda, que na intenção de refletir sobre o tema, o julgador, de forma excessiva, extrapolou os limites da linguagem coloquial, de forma propositada, passando, assim, a mensagem de que é possível aproximar a justiça do cidadão, com o uso de um discurso mais acessível às partes da demanda judicial. Essa intenção ficou bem clara no trecho em que o juiz estabelece o direito de indenizar, doravante transcrito:

Dano moral - Se a pessoa sofre um abalo, uma tristeza, um constrangimento ou uma dor, por culpa de outro, tem direito a receber uma indenização de quem lhe causou isso. Não é qualquer dorzinha que dá direito a uma compensação em dinheiro, mas a que o Sujeito 1 teve e tem, certamente, é de indenizar. Caiu, ficou desacordado, foi para o hospital, sofreu procedimentos, medo das sequelas e a 
dor que até agora sente em alguns movimentos do corpo, além de ficar sem poder trabalhar no seu ofício.

Essa indenização serve para amenizar um pouco o sofrimento do sujeito, mas também serve para Itamar lembrar que tem obrigação de cuidar da segurança daqueles que trabalham na sua casa, mesmo quando não são empregados.

A lei não fixa valores para cada caso e o Juiz tem que fazer isso com bom senso.

Não pode ser uma indenização tão pesada que vire um inferno para seu (Sujeito 2) pagar; nem muito pouco, porque aí ele paga sem problemas e não se importa se amanhã ou depois outro acidente acontece em sua casa (grifo nosso)

Numa análise aos trechos referenciados no trecho da decisão, constatou-se um excesso na linguagem empregada, em contrapartida, verifica-se ser extremamente possível a substituição de termos técnicos e expressões latinas por uma linguagem mais simples e próxima daqueles que diretamente são atingidos pelas decisões judiciais. Restringir o acesso do cidadão comum, cuja prática de letramento se funda em outros e não no letramento dominante, é negar a esses jurisdicionados o verdadeiro acesso à justiça, tal qual apregoa o texto constitucional.

Nesse sentido, iniciativas como essa citada servem para se refletir sobre uma tomada de decisão e a adoção de uma nova postura frente à necessidade de inserção do cidadão nas decisões jurídicas.

Por outro quadrante, no que tange ao poder simbólico, Bourdieu (2002) afirma que o capital simbólico adquirido pelos agentes do campo jurídico e seu poder decisório representam a palavra pública enunciada em nome de todos, veredito que resolve os conflitos reconhecidos universalmente. Acrescenta que os ritos constituintes do universo jurídico, encarnada por uma autoridade constituída é iniciada pela linguagem. Portanto, mesmo que exista toda uma estrutura e um mecanismo que sustentam esse poder simbólico, é possível minimizar esses impactos que funcionam como instrumentos de fronteira entre os agentes estatais e o cidadão comum.

Dessa forma, entende-se que o uso de uma linguagem despojada de rebuscamento, de purismo e da tecnicidade própria da seara jurídica, proporcionará a democratização do conteúdo das decisões judiciais, minimizando, portanto, a relação de dominação decorrente da dificuldade de entendimento dessas decisões e indo ao encontro do princípio constitucional de acesso à justiça.

\section{CONSIDERAÇÕES FINAIS}




\section{CONQGESSOC CIENCIAESOCIEDADE

Os textos jurídicos, emanados dos agentes públicos que deles fazem uso, devem contribuir para a eficácia da aplicação e compreensão do Direito, sem abusos de incompreensão. Privilegiar o letramento dominante em detrimento do letramento vernacular é condenar o jurisdicionado ao isolamento e ao distanciamento da justiça, numa afronta aos princípios que fregem o Estado democrático de direito.

A distorção e o uso abusivo do letramento dominante a fim de elitizar a linguagem jurídica, instrumentalizando-o como forma de poder, trazem consequências irreversíveis à justiça e à sociedade. Toda a discursão sobre a linguagem da decisões emanadas dos juízes no âmbito do poder judiciário, cujas respostas encontrou amparo no letramento dominante e no poder simbólico de Bourdieu (1989), levam à compreensão dos fenômenos que perpassam a linguagem jurídica, podendo elucidar os motivos de manutenção desta linguagem, tal como ela tem se colocado para a sociedade: distante e inacessível.

A linguagem só existe enquanto realização social. Se a linguagem jurídica tem uma dimensão dialógica Fiorin (2008), necessário estabelecer a interação com o jurisdicionado. O uso de um código gera a exclusão de determinado público, o que, no caso dos textos emanados dos julgadores no âmbito jurisdicional, afronta o princípio de acesso à justiça, como já exaustivamente afirmado, maculando, assim, a relação dialógica da linguagem.

Em se tratando de linguagem jurídica, cujo letramento dominante e o preciosismo linguístico prevalecem, como inserir o cidadão nessa relação dialógica? Como discutido no bojo do artigo, esse rebuscamento e excessos presentes nas decisões emanadas dos iminentes julgadores revelam um arrogo próprio das relações assimétricas hierarquizadas, que estruturam o poder simbólico, consoante ideia de Bourdieu (1989).

Como visto na análise do acórdão, a instauração da simplificação da linguagem jurídica mostra-se necessária no país, com o fito de efetivar o direito de acesso à Justiça. Isto posto, constata-se maior eficácia naquelas iniciativas que incentivam o legislador e os profissionais do Direito a redigirem com clareza e objetividade. Toda a argumentação tecida ao longo deste artigo teve a intenção de levar o leitor ao convencimento de que o acesso à Justiça é direito constitucional do cidadão brasileiro e que o uso de uma linguagem jurídica clara, acessível e objetiva é determinante para a efetivação desse direito. 


\section{CONOEFESOCIENCIAESOCIEDADE

\section{REFERÊNCIAS BIBLIOGRÁFICAS}

BOURDIEU, Pierre. O poder simbólico. 6 ed. Rio de Janeiro: Bertrand Brasil, 1989. Disponível em http://www.ipeq.quimica.ufg.br/up/426/o/BOURDIEU_Pierre._O_poder_simbolico.pdf. Acesso em 20 de junho de 2019.

FIORIN, José Luiz. Introdução ao pensamento de Bakhtin. São Paulo: Ática, 2008.

FREIRE, Paulo. Ideologia e educação: Reflexões sobre a não Neutralidade da Educação. Rio de Janeiro: Editora Paz e Terra, 1981.

g1.globo.com/rs/rio-grande-do-sul/noticia/2015/06/magistrado-do-rs-troca-jurisdiques-por linguagem-simples-em-sentenca.html. Acesso em 20 de junho de 2019. Acesso em 20 de junho de 2019.

http://www.ipm.org.br/ipmb_pagina.php?mpg=4.02.0.00.00\&ver. Acesso em: 20 de junho de 2019.

KLEIMAN, Ângela B. (org.). Os significados do letramento. Campinas: Mercado de Letras, 1995.

MORTATTI, Maria do Rosário Longo. Educação e Letramento. São Paulo: UNESP, 2004.

RIOS, Guilherme Veigas. Letramentos do mundo da vida e letramentos de sistemas: revisitando os letramentos dominantes. Revista Signótica - UFG, Goiás. v. 25, n. 2, 2013.

SOARES, Magda. Novas práticas de leitura e escrita: letramento na cibercultura. In: Educ. Soc., Campinas, vol.23, n. 81, p.143-160, dez. 2002. Disponível em: http://www.cedes.unicamp.br. Acesso em: 20 de junho de 2019.

STREET, Brian V. Literacy in theory and practice. Cambridge: Cambridge University Press, 1984.

TFOUNI, L. V. Adultos não alfabetizados: o avesso do avesso. Campinas: Pontes, 1988.

TFOUNI, L. V. Letramento e alfabetização. São Paulo: Cortez, 1995. 